\title{
Plackett- Burman Design for the Screening of Media Component for Anthracene Degradation by Sphingobium Yanoikuyae Strain ANT3D
}

\author{
Rahul K. Rajpara*, Dushyant R. Dudhagara, Jwalant K. Bhatt, Haren B. Gosai and \\ Bharti P. Dave*
}

Department of Life Sciences, Sardar Vallabhbhai Patel Campus, Maharaja Krishnakumarsinhji Bhavnagar University, Bhavnagar, Gujarat- 364002, India

Received: October 25, 2016; Accepted: December 1, 2016; Published: December 7, 2016

*Corresponding author: Rahul K. Rajpara and Bharti P. Dave, Department of Life Sciences, Sardar Vallabhbhai Patel Campus, Maharaja Krishnakumarsinhji Bhavnagar University, Bhavnagar, Gujarat- 364002, India, Tel: +91 $2782519824 ;$ fax: +91 278 2521545; E-mail: rkrajpara2008@gmail.com,bpd8256@gmail.com

\begin{abstract}
Anthracene, a three ring Low Molecular Weight (LMW) Polycyclic Aromatic Hydrocarbon (PAHs) has carcinogenic mutagenic and teratogenic effects on biota. Using various selective media, a total 33 isolates were obtained from various media. Amongst these 33 isolates, 6 isolates exhibited capability to utilize multiple PAHs as sole source of carbon and energy. Amongst 6 isolates, Sphingobium yanoikuyae strain ANT3D showed maximum degradation of anthracene, S. yanoikuyae strain ANT3D isolated from crude oil polluted sites along the Gulf of Kutch. Plackett- Burman experimental design was used to evaluate the medium components for significant anthracene degradation. The most significant variables affecting anthracene degradation were found to be $\mathrm{KH}_{2} \mathrm{PO}_{4}, \mathrm{~K}_{2} \mathrm{HPO}_{4}$, and $\mathrm{CaCl}_{2}$. These components were further selected for optimization to achieved maximum degradation by response surface methodology.
\end{abstract}

Keywords: Anthracene; LMW PAHs; Degradation; PlackettBurman Design

\section{Introduction}

Polycyclic Aromatic Hydrocarbons (PAHs) comprise a large and heterogeneous group of organic contaminants that are formed either naturally or due to anthropogenic activities. Last few years, PAHs are compounds of intense public concern due to their thermodynamic stability of benzene moiety and potentially deleterious effects on human, environment and ecological health. The cleanup of such type of pollutant using innate metabolic capability of bacteria is a promising approach for bioremediation of recalcitrant compound [1,2]. Microbial degradation can be increased by manipulating nutritional requirements. A number of factors that influences the PAHs degradation by bacteria and amongst them, components of the growth are an important factor to improve the degradation rate of PAHs. The "one factor at time approach" is time consuming and expensive and does not reflect the combined effect of all variables involved. Moreover, it requires a large number of experiments for the determining or screening of components. Use of statistical model for the screening of the variables can eliminate these limitations of "one factor at time" approach. Statistical method has several advantages as being rapid, reliable, less expensive, screening of number of variables, understanding of effect of variable at various coded level [3]. Numbers of statistical models are available amongst them Plackett- Burman (PB) and Response Surface Methodology (RSM) is most widely used statistical models. Two level fractional factorial designs (PB design) is used for the screening of the variable with small number of experimental runs instead of using more extensive factorial design, which would furnish more detail explanation [4].

The present paper discusses screening of suitable medium components for degradation of anthracene by Sphingobium yanoikuyae strain ANT3D using Plackett-Burman design.

\section{Materials and Methods}

\section{Organism and Medium}

Multiple PAHs degrading isolate S. yanoikuyae strain ANT3D was selected for optimization of $\mathrm{BH}$ medium components as $\mathrm{MgSO}_{4}, \mathrm{CaCl}_{2}, \mathrm{KH}_{2} \mathrm{PO}_{4}, \mathrm{~K}_{2} \mathrm{HPO}_{4}, \mathrm{NH}_{4} \mathrm{NO}_{3}$, and $\mathrm{FeCl}_{3}$. The $S$. yanoikuyae strain ANT3D was routinely grown on $\mathrm{BH}$ medium amended with anthracene at concentration of $50 \mathrm{mg} / \mathrm{L}$ and stored at $4^{\circ} \mathrm{C}$ until use [5].

\section{Enrichment and isolation of PAHs degrading bacteria using selective media}

Soil samples were collected from crude oil contaminated saline sites near Gulf of Kutch, Jamnagar coast (latitude 22 $344^{\prime} 17.50^{\prime \prime}$ ${ }^{\circ} \mathrm{N}, 70^{\circ} 10^{\prime} 53.00^{\prime \prime}{ }^{\circ} \mathrm{E}$, longitude) Gujarat, India. Isolation of PAHs degrading bacteria was executed by using various selective media and techniques as described below: Nagel and Andreesen's (NA) [6] and Bushnell-Hass (BH) [7] media were used for enrichment of PAHs degrading bacteria from crude oil polluted marine sediment samples. For this, $1 \mathrm{~g}$ of polluted sediment samples were added to $10 \mathrm{~mL} \mathrm{BH}$ medium in test tube and vortexed for $1 \mathrm{~min}$. 
The tubes were incubated for $10 \mathrm{~min}$ at room temperature for soil particles to settle down. From this $1 \mathrm{~mL}$ supernatant was added to $50 \mathrm{~mL} \mathrm{NA}$ and BH media in $250 \mathrm{~mL}$ Erlenmeyer flasks, amended with $50 \mathrm{mg} / \mathrm{L}$ of each PAHs as Naphthalene (Nap), Phenanthrene (Phe), Anthracene (Ant), Fluoranthene (Flt), Pyrene (Pyr) and Chrysene(Chr), with final concentration $\Sigma$ PAHs of $300 \mathrm{mg} / \mathrm{L}$. The flasks were kept on an environmental shaker (Excella E24R, New Brunswick, USA) at $150 \mathrm{rpm}$ at an ambient temperature. After seven days of enrichment, $100 \mu \mathrm{L}$ samples from the flask was spread onto different selective media such as actinomycetes isolation agar, $\mathrm{R}_{2} \mathrm{~A}$ agar, Lowenstein Jensen (LJ) agar, humic acidvitamin agar (HV agar), Pseudomonas isolation agar, Nagel and Andreesen's agar and Bushnell and Hass agar media.

\section{Identification of the most efficient PAH degrading isolate}

Molecular identification of potent PAHs degrading isolate was carried out using partial 16SrRNA sequencing and the obtained sequence was analyzed using BLAST from NCBI server. The sequences of neighbor strains were downloaded and aligned through Clustal W 1.6 program at http://www.ebi.ac.uk/clustalw.

\section{Inoculum preparation}

The inoculum was prepared by transferring $0.1 \mathrm{~mL}$ of culture into $100 \mathrm{~mL} \mathrm{BH}$ containing $0.1 \%$ yeast extract in 250 $\mathrm{mL}$ Erlenmeyer flask and incubated at $30^{\circ} \mathrm{C}$ for $24 \mathrm{~h}$. Cells were harvested in sterile tubes by centrifugation at $10000 \mathrm{rpm}$ for 10 min. Pellet obtained was resuspended in phosphate buffer to adjust optical density to 1.0 at $600 \mathrm{~nm} .1 \mathrm{~mL}$ of prepared inoculum was added in experimental runs.

\section{Optimization for anthracene degradation}

Screening of components of Bushnell-Haas (BH) medium using Plackett-Burman (PB) design: The first step in optimization study was to identify medium components that have significant effect on anthracene degradation. PB design is a useful tool to identify the most affecting factor from the large number of independent variables. Placket-Burman design allows the evaluation of $\mathrm{N}-1$ variable by $\mathrm{N}$ number of experiments (where $\mathrm{N}$ is multiple of four). Each row and columns contain equal number of positive $(\mathrm{N}+1 / 2)$ and negative $(\mathrm{N}-1 / 2)$ signs. As a preliminary optimization experiment, $\mathrm{BH}$ medium components as $\mathrm{MgSO}_{4}, \mathrm{CaCl}_{2}, \mathrm{KH}_{2} \mathrm{PO}_{4}, \mathrm{~K}_{2} \mathrm{HPO}_{4}, \mathrm{NH}_{4} \mathrm{NO}_{3}$ and $\mathrm{FeCl}_{3}$ have been evaluated based on the PB Design. Total six variables were tested at two different levels represented as high concentration (+1) and low concentration (-1). Variable which showed $95 \%$ confidence level was selected for further optimization by CCD. Table 1 shows independent variables and their high and low values used in the experimental design matrix. Each row represents a trial and column represents independent variable. The effect of variable was determined by the following equation.

$$
Y=\beta_{0}+\Sigma \beta_{1} X i
$$

Where, $Y$ is the response (anthracene degradation), $\beta_{0}$ is the model intercept, $\beta_{1}$ is the linear coefficient and $X i$ is the level of independent variable [4].
In the present study, six assigned variables were screened in twelve experimental designs. Anthracene degradation by $S$. yanoikuyae strain ANT3D was estimated on $3^{\text {rd }}$ day. The variables that had significant main effect on the response were considered for further full factorial RSM study.

\section{Extraction and estimation of residual anthracene}

For estimating residual anthracene, equal volume of DCM was added to the $\mathrm{BH}$ medium and sonicated for $5 \mathrm{~min}$ thrice with one minute of rest. Solvent phase was collected and the same procedure was repeated twice. Aqueous phase was removed by $\mathrm{Na}_{2} \mathrm{SO}_{4}$ and the collected solvent was pooled. Solvent phase was reduced using rotary vacuum evaporator (Büchi R215, Switzerland). After evaporation of solvent, solid white crystals were redissolved in known amount of DCM prior to analysis by GC-MS as suggested by [8-10].

\section{Results and Discussion}

\section{Isolation and Identification}

A total 33 different isolates (designated as RR 1 to RR 33) were selected on the basis of their morphological characteristics. These isolates were further screened for the utilization of multiple PAHs. Out of 33 isolates, isolates RR- 6 had been considered as most potent multiple PAHs degrading isolate based on liquid culture experiment (data was not shown) studies. The isolate RR 6 was identified using 16S rDNA sequencing (Genei Pvt. Ltd., Bangalore, India). rRNA sequencing and BLASTN analysis of $16 \mathrm{~S}$ rRNA gene sequence $(1,347 \mathrm{bp})$ of strain RR 6 showed maximum sequence similarity (100\%) with Sphingobium yanoikuyae. The sequence has been deposited in NCBI with accession number KP276679. The strain was designated with S. yanoikuyae strain ANT3D. Figure 1 shows the phylogenetic tree of $S$. yanoikuyae strain ANT3D with closely related bacterial species.

\section{Screening of media components using Plackett- Burman design}

Two level fractional factorial PB design was executed using statistical software Minitab Version 16, that screens $\mathrm{k}$ variable in $\mathrm{k}+1$ experimental runs. Moreover the design is orthogonal in nature and so gives information about the pure effect of each variable. It does not give an idea about interaction between the variables [4]. All six constituents of $\mathrm{BH}$ medium $\left(\mathrm{MgSO}_{4}, \mathrm{CaCl}_{2}\right.$, $\mathrm{KH}_{2} \mathrm{PO}_{4}, \mathrm{~K}_{2} \mathrm{HPO}_{4}, \mathrm{NH}_{4} \mathrm{NO}_{3}$ and $\mathrm{FeCl}_{3}$ ) were studied for their effect on anthracene degradation by $S$.yanoikuyae strain ANT3D. Experiments were performed as per combinations of the factors shown in Table 1. Table 2 represents the fallouts of PB design experiment with the main effects, standard error and $p$ values calculated of each component for anthracene degradation. The components were screened at the confidence level of $95 \%$ on the basis of their effects. If the component showed significance at or above $95 \%$ confidence level and its effect was negative, it indicated that the component was effective in anthracene degradation but the amount required was lower than the indicated as low $(-)$ in PB design experiment. If the effect was positive, a higher 
Table 1: PB design matrix of six variables in terms of actual and coded values

\begin{tabular}{|c|c|c|c|c|c|c|c|c|}
\hline $\begin{array}{l}\text { Run } \\
\text { No. }\end{array}$ & $\begin{array}{l}\mathrm{MgSO}_{4} \\
(\mathrm{~g} / \mathrm{L})\end{array}$ & $\begin{array}{l}\mathrm{CaCl}_{2} \\
(\mathrm{~g} / \mathrm{L})\end{array}$ & $\begin{array}{c}\mathrm{KH}_{2} \mathrm{PO}_{4} \\
(\mathrm{~g} / \mathrm{L})\end{array}$ & $\begin{array}{c}\mathrm{K}_{2} \mathrm{HPO}_{4} \\
(\mathrm{~g} / \mathrm{L})\end{array}$ & $\begin{array}{c}\mathrm{NH}_{4} \mathrm{NO}_{3} \\
(\mathrm{~g} / \mathrm{L})\end{array}$ & $\begin{array}{l}\mathrm{FeCl}_{3} \\
(\mathrm{~g} / \mathrm{L})\end{array}$ & $\begin{array}{c}\text { Predicted } \\
\text { D (\%) }\end{array}$ & D (\%) \\
\hline 1 & $0.15(-1)$ & $0.015(-1)$ & $1.25(1)$ & $1.25(1)$ & $1.25(1)$ & $0.03(-1)$ & 29.66 & 29.89 \\
\hline 2 & $0.25(1)$ & $0.015(-1)$ & $1.25(1)$ & $1.25(1)$ & $0.75(-1)$ & $0.06(1)$ & 25.49 & 23.20 \\
\hline 3 & $0.15(-1)$ & $0.025(-1)$ & $0.75(-1)$ & $0.75(-1)$ & $0.75(-1)$ & $0.06(1)$ & 20.12 & 17.66 \\
\hline 4 & $0.25(1)$ & $0.025(1)$ & $0.75(-1)$ & $1.25(1)$ & $1.25(1)$ & $0.03(-1)$ & 21.47 & 21.68 \\
\hline 5 & $0.15(-1)$ & $0.015(-1)$ & $0.75(-1)$ & $1.25(1)$ & $1.25(1)$ & $0.06(1)$ & 9.44 & 6.66 \\
\hline 6 & $0.15(-1)$ & $0.015(-1)$ & $0.75(-1)$ & $0.75(-1)$ & $0.75(-1)$ & $0.03(-1)$ & 11.50 & 12.02 \\
\hline 7 & $0.25(1)$ & $0.025(-1)$ & $1.25(1)$ & $0.75(-1)$ & $1.25(1)$ & $0.06(1)$ & 28.11 & 26.07 \\
\hline 8 & $0.25(-1)$ & $0.015(1)$ & $1.25(1)$ & $0.75(-1)$ & $0.75(-1)$ & $0.03(-1)$ & 23.51 & 23.12 \\
\hline 9 & $0.25(1)$ & $0.025(1)$ & $0.75(-1)$ & $1.25(1)$ & $0.75(-1)$ & $0.03(-1)$ & 25.50 & 25.30 \\
\hline 10 & 0.151() & $0.025(1)$ & $1.25(1)$ & $1.25(1)$ & $0.75(-1)$ & $0.06(1)$ & 42.32 & 47.18 \\
\hline 11 & $0.15(1)$ & $0.025(1)$ & $1.25(1)$ & $0.75(-1)$ & $1.25(1)$ & $0.03(-1)$ & 36.30 & 35.96 \\
\hline 12 & $0.25(-1)$ & $0.015(-1)$ & $0.75(-1)$ & $0.75(-1)$ & $1.25(1)$ & $0.06(1)$ & 0.00 & 4.01 \\
\hline
\end{tabular}

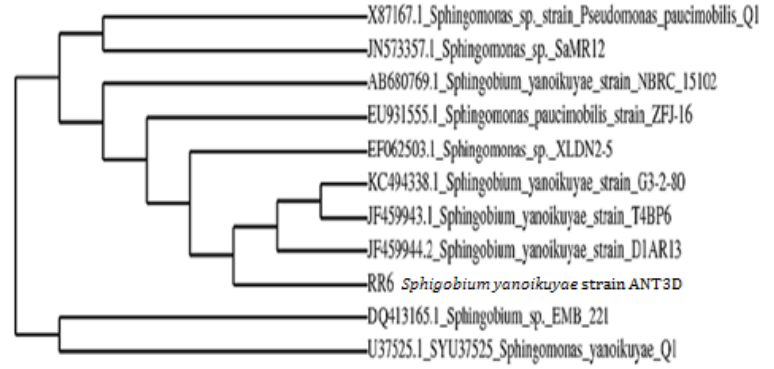

Figure 1: Phylogenetic tree showing nearest neighbors of Sphigobium yanoikuyae strain ANT3D.

concentration than the indicated high value $(+)$ was required during further optimization studies [4]. The components $\mathrm{KH}_{2} \mathrm{PO}_{4}$, $\mathrm{CaCl}_{2}$ and $\mathrm{K}_{2} \mathrm{HPO}_{4}$ showed significant main effects on anthracene degradation at $95 \%$ confidence level, having $p$ value $0.001,0.002$ and 0.043 respectively (Table 2 ).

The confidence level of components $\mathrm{MgSO}_{4}, \mathrm{NH}_{4} \mathrm{NO}_{3}$ and $\mathrm{FeCl}_{3}$ were below $95 \%$ for degradation of anthracene and hence were considerved insignificant. Table 2 shows that $\mathrm{MgSO}_{4}, \mathrm{NH}_{4} \mathrm{NO}_{3}$ and $\mathrm{FeCl}_{3}$ were insignificant with $p$ value $0.101,0.121$ and 0.134 respectively, indicating that the proportions of these three components in the medium were not at appropriate levels to achieve maximum anthracene degradation. Hence, they were not considered for subsequent RSM analysis. So, further manipulation in the selection of levels for insignificant components of $\mathrm{BH}$ medium can increase the efficiency of anthracene degradation with the same kind of statistical design.

The normal chart of standardized effect illustrates the order of significance of the variables i.e. $\mathrm{KH}_{2} \mathrm{PO}_{4}, \mathrm{CaCl}_{2}, \mathrm{~K}_{2} \mathrm{HPO}_{4} \mathrm{MgSO}_{4}$, $\mathrm{NH}_{4} \mathrm{NO}_{3}$ and $\mathrm{FeCl}_{3}$, affecting anthracene degradation (Figure 2). Out of the six variables examined, $\mathrm{KH}_{2} \mathrm{PO}_{4}, \mathrm{CaCl}_{2}$ and $\mathrm{K}_{2} \mathrm{HPO}_{4}$ had significant effects at $99.95 \%, 99.90 \%$ and $97.85 \%$ confidence level respectively. These three significant variables had positive main effect on anthracene degradation (Table 2) indicating that anthracene degradation can be enhanced if these variables are manipulated.The results obtained by ANOVA (Table 3) revealed that the main effects of the factors in the model term were highly significant $(p=0.003)$. By putting each component at different levels in each combination, anthracene degradation achieved was $47.18 \%$ (Table 1 and Run No. 10) on $3^{\text {rd }}$ day. The above data of PB design clearly indicates that the model is highly significant. Hence, based on the data obtained from $\mathrm{PB}$ design, $\mathrm{KH}_{2} \mathrm{PO}_{4}, \mathrm{CaCl}_{2}$ and $\mathrm{K}_{2} \mathrm{HPO}_{4}$ were chosen for further optimization study by using CCD of RSM.

The similar kind of experiment was carried out [11] for the screening of medium component for the optimization of phenol degradation by Alcaligenes faecalis. Statistical model for the screening of medium components by Plackett-Burman design for lactic acid production by Lactobacillus sp. KCP01[4]. PlackettBurman design to evaluate medium components for lipase production by Rizopus arrhizus MTCC2233 was demonstrated [12].

\section{Conclusion}

The statistical design of experiments offers efficient methodology to identify the significant variables. The most significant factors identified by Plackett- Burman design were $\mathrm{KH}_{2} \mathrm{PO}_{4}, \mathrm{CaCl}_{2}$ and $\mathrm{K}_{2} \mathrm{HPO}_{4}$. These significant factors identified were considered for the next stage in the medium optimization technique using response surface methodology.

\section{Acknowledgement}

The authors are gratefully acknowledge the financial support by Earth System Sciences organization (ESSO), Ministry of Earth Sciences, Government of India, New Delhi and Gujarat State Biotechnology Mission (GSBTM), Gandhinagar, Gujarat. 


\begin{tabular}{|c|c|c|c|c|c|}
\hline \multicolumn{6}{|c|}{ Table 2: Estimated effects and coefficients of degradation (\%) of } \\
anthracene as analyzed by PB design \\
\hline Term & $\begin{array}{c}\text { Main } \\
\text { effect }\end{array}$ & Coefficient & $\begin{array}{c}\text { SE } \\
\text { Coefficient }\end{array}$ & $\boldsymbol{t}$ & $\boldsymbol{p}$ \\
\hline Constant & & 22.729 & 1.081 & 21.03 & 0.00 \\
\hline $\mathrm{MgSO}_{4}$ & -4.332 & -2.166 & 1.081 & -2.00 & 0.101 \\
\hline $\mathrm{CaCl}_{2}$ & 12.492 & 6.246 & 1.081 & 5.78 & 0.002 \\
\hline $\mathrm{KH}_{2} \mathrm{PO}_{4}$ & 16.348 & 8.174 & 1.081 & 7.56 & 0.001 \\
\hline $\mathrm{K}_{2} \mathrm{HPO}_{4}$ & 5.845 & 2.922 & 1.081 & 2.70 & 0.043 \\
\hline $\mathrm{NH}_{4} \mathrm{NO}_{3}$ & -4.035 & -2.018 & 1.081 & -1.87 & 0.121 \\
\hline $\mathrm{FeCl}_{3}$ & -3.865 & -1.932 & 1.081 & -1.79 & 0.134 \\
\hline $\mathbf{R 2}=\mathbf{0 . 9 5 6 R 2}$ & Adjusted R2 $\mathbf{0 . 9 0 3 2}$ & & \\
\hline \multicolumn{5}{|c|}{} \\
\hline
\end{tabular}

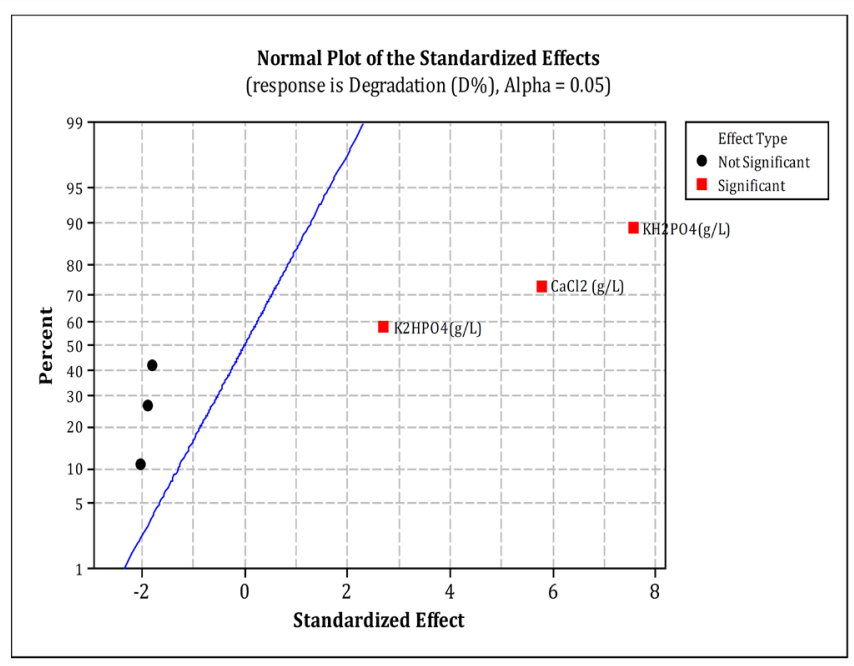

Figure 2: Normal plot of the Standardized Effect.

\begin{tabular}{|c|c|c|c|c|c|c|}
\hline \multicolumn{7}{|c|}{ Table 3: ANOVA for PB design } \\
\hline Source & DF & Seq SS & $\begin{array}{c}\text { Adjusted } \\
\text { SS }\end{array}$ & Adjusted MS & $\boldsymbol{F}$ & $p$ \\
\hline Main Effects & 6 & 1522.37 & 1522.37 & 253.73 & 18.11 & 0.003 \\
\hline $\begin{array}{l}\text { Residual } \\
\text { Error }\end{array}$ & 5 & 70.06 & 70.06 & 14.01 & & \\
\hline Total & 11 & 1592.43 & & & & \\
\hline
\end{tabular}

\section{References}

1. Chauhan A, Fazlurrahman, Oakeshott JG, Jain RK. Bacterial metabolism of polycyclic aromatic hydrocarbons: Strategies for bioremediation. Indian J Microbiol. 2008;48(1):95-113. doi: 10.1007/s12088-0080010-9.

2. Dudhagara DR, Rajpara RK, Bhatt JK, Gosai HB, Sachaniya BK, Dave BP. Distribution, sources and ecological risk assessment of PAHs in historically contaminated surface sediments at Bhavnagar coast, Gujarat, India. Environmental Pollution. 2016;213:338-346.

3. V. Gohel, T. Chaudhary, P. Vayas, H.S. Chhatpar. Statistical screening of medium components for the production of chitinase by marine isolate Pantoea dispersa. Biochemical Engineering Journal. 2006;28:50-56.

4. K. Chauhan, U. Trivedi, K.C. Patel. Statistical screening of medium components by Plackett-Burman design for lactic acid production by Lactobacillus sp. KCP01 using date juice. Bioresour Technol. 2007;98(1):98-103.

5. Rajpara RK, Dudhagara DR, Bhatt JK, Ghevariya CM, Domadiya TB, et al. Isolation and Investigation of Biodegradation Potential of Multiple Polycyclic Aromatic Hydrocarbons (PAHs) Degrading Marine Bacteria near Bhavnagar Coast, India. Journal of Marine Biology \& Oceanography. 2015;4:2.

6. R.M. Atlas. Handbook of media for environmental microbiology, second ed. CRC Press, Taylor \& Francis Group, USA, 2005.

7. L.D. Bushnell, H.F. Hass. The utilization of certain hydrocarbons by microorganisms. J Bacteriol. 1941;41(5):653-73.

8. D’Souza-Ticlo, S. Garg, C. Raghukumar. Effects and interactions of medium components on laccase from a marine-derived fungus using response surface methodology. Mar Drugs. 2009;7(4):672-88. doi: $10.3390 / \mathrm{md} 7040672$.

9. C.M. Ghevariya, J.K. Bhatt, B.P. Dave. Enhanced chrysene degradation by halotolerant Achromobacter xylosoxidans using response surface methodology. Bioresour Technol. 2011;102(20):9668-74. doi: 10.1016/j.biortech.2011.07.069.

10. Bhatt JK, Ghevariya CM, Dudhagara DR, Rajpara RK, Dave BP. Application of response surface methodology for rapid chrysene biodegradation by newly isolated marine-derived fungus Cochliobolus lunatus strain CHR4D. J Microbiol. 2014;52(11):908-17. doi: 10.1007/ s12275-014-4137-6.

11.S. Mandal, B. Bhunia, Anjukumar, D. Dasgupta, T. Mandal, S. Datta S. Bhattacharya. A statistical approach for optimization of media components for phenol degradation by Alcaligenes faecalis using Plackett-Burman and response surface methodology, Desalination and Water treatment. 2013;51:6058-6069.

12.A. Rajendran, V. Thangavelu, Statistical experimental design for evaluation of medium components for lipase production by Rhizopus arrhizus MTCC 2233. LWT- Food Sciences and Technology. 2009;42:985-992. 